\title{
Soft Capsule plus Tablet Dosage Form
}

National Cancer Institute

\section{Source}

National Cancer Institute. Soft Capsule plus Tablet Dosage Form. NCI Thesaurus. Code C149367.

Combination package consisting of a soft capsule and a tablet. 